\title{
Feeding environment and the activity-stress ulcer
}

\author{
WILLIAM P. PARE* \\ Pavlovian Research Laboratory, VA Hospital, Perry Point, Maryland 21902
}

\begin{abstract}
Rats were housed in standard activity cages and fed $1 \mathrm{~h}$ each day. One group of activity rats were fed in their activity cages, and another group of activity rats were fed in the colony home cages in which they resided before being moved to the activity wheel. The latter operation was designed to eliminate novelty stress inherent in the activity wheel environment which would suppress feeding. However, home cage feeding rats ate less than control rats, and had as many ulcers as activity rats fed in the activity wheel. Novelty stress, as defined by this study, did not contribute significantly to the development of the activity-stress ulcer.
\end{abstract}

If rats are housed in activity-wheel cages, allowed continuous access to the running wheel, and fed only $1 \mathrm{~h}$ each day, some of these rats will die within 4 to 12 days and reveal extensive lesions of the glandular stomach. On the other hand, control rats with the same feeding schedule and living in standard laboratory cages will survive and reveal lesion-free stomachs (Barboriak \& Knoblock, 1972; Pare, 1974). Since the activity variable seemed to contribute significantly to these particular stomach lesions, Paré and Houser (1973) gave these lesions the designation of "activity-stress ulcers." This work was stimulated by the "self-starvation" concept of Routtenberg and Kuznesof (1967) who had reported the consummatory pattern of rats under similar environmental and feeding conditions. One remarkable characteristic of this phenomenon is the fact that after the $1-\mathrm{h}$ feeding schedule is initiated, daily running activity increases on consecutive days whereas daily food intake diminishes. Therefore, the progressive depression in daily food intake does not support the parallel high energy expenditure. Routtenberg (1968) has suggested that the depression of daily feeding may be partly due to the stress of being housed in a novel environment. The operation of moving the animal from its living quarters in the colony room to the new environment of the activity wheel may initiate affective states which inhibit consummatory behavior (Routtenberg, 1968). In the present study, an attempt was made to reduce the incidence of activity stress ulcers by mitigating novelty stress and allowing activity rats to have their 1 -h feeding period in their original colony home cages. Another group of activity rats were restricted to their activity cages during the feeding period.

\section{METHOD}

\section{Animals and Apparatus}

Ss consisted of 42 male Sprague-Dawley rats (218-248 g). All

*The author wishes to thank Christine Thompson for her technical assistance. Gratitude is extended to Luther Gilliam of the Medical nlustration Service, VA Hospital, Perry Point, Maryland, for the photographic illustrations. rats were individually housed in single cages $(25 \times 17.5 \times 17.5 \mathrm{~cm})$. Cages were located in the same room with the activity running wheel cages. Three weeks later, rats were equated for body weight and were assigned to one of the following three treatment groups: control $(n=12)$, home-cage feeding $(n=12)$ and avtivity-cage feeding $(n=18)$. Rats in the home-cage feeding and activity-cage feeding groups were individually placed in standard Wahmann activity wheel cages. Each activity wheel included a $25 \times 15 \times 13 \mathrm{~cm}$ adjoining cage. Rats in activity wheel cages had continuous access to the running wheel. Control rats remained in their own single cages. Immediately after rats were assigned to the various treatment conditions, food was withdrawn from all animals. Water was always available to all rats. The following day all rats were weighed and fed between 9-10 am. For the activity-cage feeding group, a rat was removed from the cage and placed on the weighing scale. While still on the scale, the food jar was placed in the cage adjoining the running wheel. The rat was then removed from the scale and returned to its activity cage for feeding. After the 1-h feeding period the rat was again removed from its cage; the food jar was retrieved from the activity cage and the rat was returned to its activity cage. Rats in the home-cage feeding group were handled in the same fashion as the activity-cage feeding rats, except that the food jar was placed in the single cage in which the rat resided during the 3 weeks preceding the experimental period. In this fashion, home-cage feeding rats had their 1-h feeding period in their previous living environment. These cages had not been washed and were located no more than $9 \mathrm{ft}$ away from the activity cages. Control rats were handled in the same fashion as activity rats with respect to the weighing-feeding procedure and were fed in their own single cages. In this manner all rats were handled the same number of times each day. Rats were fed granular Purina Lab Chow. Body weight and the amount of food consumed during the 1-h feeding period were recorded each day. Room temperature was maintained at $74-76^{\circ} \mathrm{F}$. Room lights were on between 6 am and $6 \mathrm{pm}$. If a rat died, the stomach was removed and inspected for ulcers. The number of ulcers and cumulative length (millimenters) of the ulcers were recorded. The study was terminated after 21 days; all surviving rats were then killed and their stomachs were inspected for ulcers.

\section{RESULTS}

Allowing activity rats to eat in their home cages did not facilitate feeding. As a matter of fact, an analysis of variance evaluation of food consumption data for the first 6 days revealed differential consumption for the three treatment groups $(\mathrm{F}=3.47, \mathrm{df}=2 / 39, \mathrm{p}<.05)$, with this difference being attributable to the smaller food consumption of the home-cage feeding rats as 


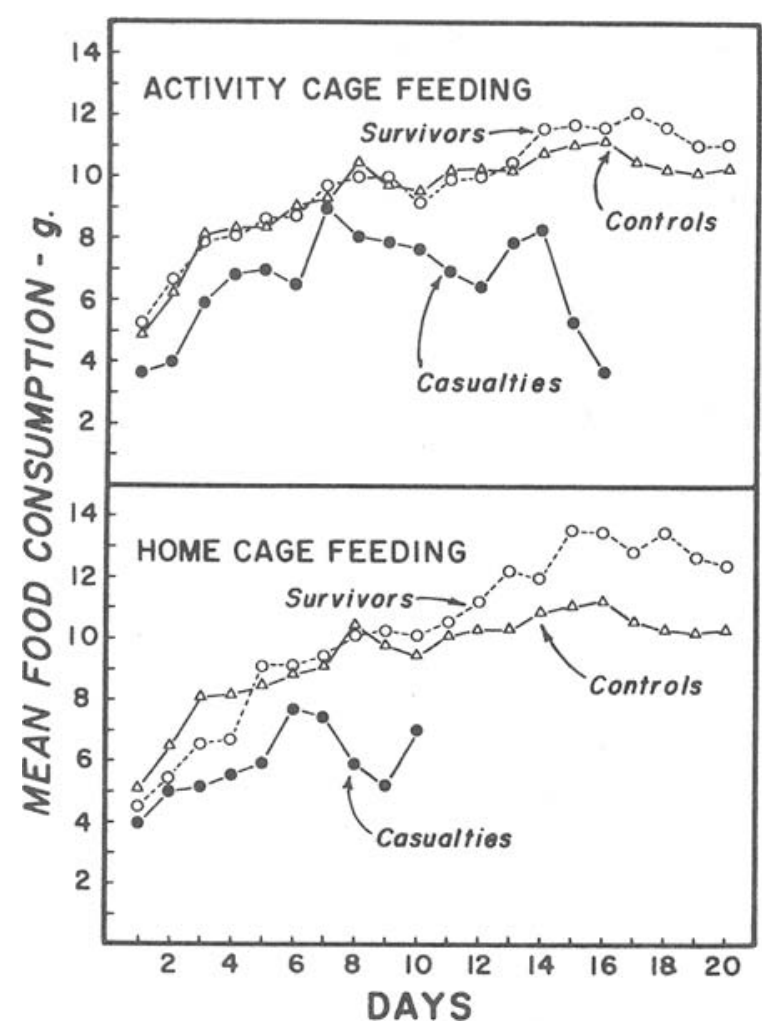

Fig. 1. Mean daily 1-h food consumption for the activity-cage feeding group, the home-cage feeding, and the control group. The two activity-cage groups are separated into those animals which died ("casualties") and those which lived through the experimental period ("surviviors"). The numbers in parentheses indicate the number of rats represented by that particular data point. Data for control rats are presented in both the upper and lower panels.

compared to control rats $(F=6.16$, $\mathrm{df}=1 / 39$, $\mathrm{p}<.025)$. These data are illustrated by Fig. 1 . Home-cage feeding rats also died sooner than activity-cage feeding rats. Figure 2 illustrates these data in terms of cumulative mortality, but a Kolmogorov-Smirnov analysis of these data showed that

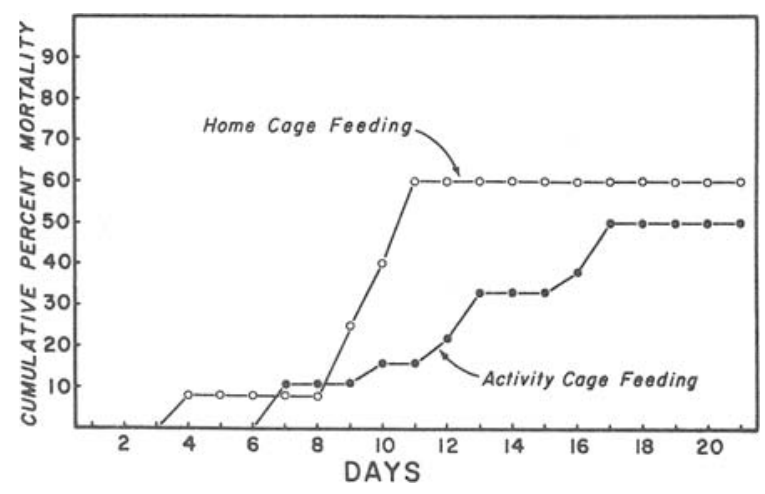

Fig. 2. Cumulative percent mortalities for the activity-wheel rats feeding in their home cages and activity-wheel rats feeding. in the activity apparatus.

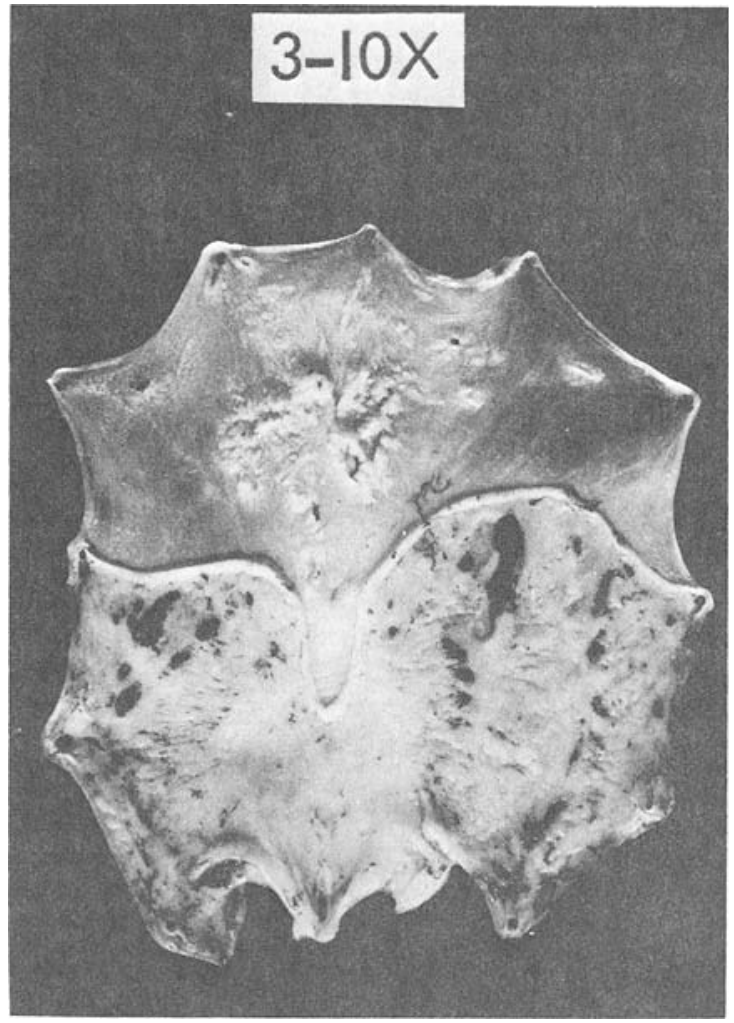

Fig. 3. Stomach of an activity-wheel rat from the home-cage feeding treatment group showing lesions in the corpus of the stomach.

home-cage feeding rats did not die at a faster rate than the activity-cage feeding rats $\left(\chi^{2}=3.75, p=0.15\right)$.

Figure 3 illustrates a stomach from a typical activity rat. Note that the pathology is restricted almost exclusively to the corpus of the stomach. Ulcer incidence for the three treatment groups is summarized by Table 1 . A t-test comparison between the two activity-cage groups for either the mean number of ulcers per animal or the mean cumulative length of ulcers per animal proved to be nonsignificant.

A preliminary assumption in this study was that the novelty of exposure to the activity environment was stressful and consequently inhibited feeding during the

Table 1

Summary of Stomach Pathology for the Three Treatment Conditions

\begin{tabular}{|c|c|c|c|c|}
\hline Treatment & $\mathrm{n}$ & $\begin{array}{c}\text { Rats } \\
\text { With } \\
\text { Ulcers }\end{array}$ & $\begin{array}{c}\text { Mean } \\
\text { Ulcers } \\
\text { Per } \\
\text { Rat }\end{array}$ & $\begin{array}{c}\text { Mean } \\
\text { Length } \\
(\mathrm{mm})\end{array}$ \\
\hline Home Cage Feeding & 12 & 7 & 19.5 & 36.0 \\
\hline Activity Cage Feeding & 18 & 9 & 17.2 & 26.6 \\
\hline Control & 12 & 0 & & \\
\hline
\end{tabular}


1-h feeding period. Having activity wheel rats feed in their home cage environment was an experimental operation designed to reduce this hypothetical novelty stress. However, this operation failed to alleviate the feeding depression effect. Activity rats feeding in the activity wheel apparatus ate approximately the same amount of food as controls. Only the activity rats feeding in their home cage ate less than control animals. This effect cannot be attributable to differential handling, since all animals were handled for the same amount and number of times. Evidently novelty, as explored by the present study does not contribute significantly to the development of the activity-stress ulcer.

\section{REFERENCES}

Barboriak, J. J., \& Knoblock, H. W. Gastric lesions in food-restricted young rats. Proceedings of the Society of Experimental Biology \& Medicine, 1972, 141, 830-832.

Paré, W. P. The influence of food consumption and running activity on the activity-stress ulcer in the rat. American Journal of Digestive Diseases, 1974, in press.

Paré, W. P., \& Houser, V. P. A ctivity and food-restriction effects on gastric glandular lesions in the rat: The activity-stress ulcer. Bulletin of the Psychonomic Society, 1973, 2, 213-214.

Routtenberg A. "Self-starvation" of rats living in activity wheels: Adaptation effects. Journal of Comparative \& Physiological Psychology, 1968, 66, 234-238.

Routtenberg, A., \& Kuznesof, A. W. Self-starvation of rats living in activity wheels on a restricted feeding schedule. Journal of Comparative \& Physiological Psychology, 1967, 64, 414-421.

(R eceived for publication August 27, 1974.)

\title{
The effect of amygdalectomy on long-term retention of an undertrained classically conditioned fear response*
}

\author{
MELVIN L. GOLDSTEIN $\dagger$ \\ Indiana University at Kokomo, Kokomo, Indiana 46901
}

\begin{abstract}
Rats trained in the classical conditioning fear response were subjected to amygdalectomy $24 \mathrm{~h}$ after conditioning and were tested for retention 4 days and 4-7 weeks postoperatively. The results of the experiment indicated that amygdalectomy disrupted the intermediate and long-term retention of the classically conditioned fear response. There was no recovery of performance after the amygdalectomy. The experiment confirms previous reports of retention deficits after amygdalectomy in undertrained Ss, but does not corroborate previous reports of recovery of function, with additional training, after amygdalectomy.
\end{abstract}

Brady, Schreiner, Geller, and Kling (1954) have reported acquisition deficits in amygdalectomized cats trained in the active avoidance conditioning situation. They did not, however, report any effect of amygdalectomy on retention of a preoperatively learned avoidance task. Horvath (1963) replicated these findings for acquisition and, in addition, reported retention

*The experiment reported in this paper was conducted at the Physiological Psychology Laboratory of Syracuse University. Preparation of this report was supported in part by a supply Preparation of this report was supported in part by the Indiana University Office of Research and Advanced Studies (Grant 26-631-32) and by Summer Faculty Fellow ships awarded by Indiana University.

+Charles Borneman. Jr. made the drawings for publication. Rita Martin typed the manuscript. The writer wishes to express hita Martin typed the manuscript. The writer wishes to exprestion to his wife Daidee for her patience during the preparation of this report and to William L. Stoller for a critical reading of the manuscript. deficits in cats after amygdalectomy. Fonberg, Brutkowski, and Mempel (1962) have reported that, in dogs, an incompletely learned classical defensive CR was disrupted by amygdalectomy but recovered after additional training. Amygdalectomy had no effect, however, on the retention of an overtrained avoidance response. Thatcher and Kimble (1966) have reported that preoperatively overtrained rats showed little or no retention deficit of an avoidance response after bilateral amygdalectomy, while animals trained to criterion and given no overtraining showed a marked retention deficit.

The integrity of the amygdaloid complex is, presumably, essential for the retention of fear-motivated behavior in cats, rats, and dogs. Judging from the 